\title{
Internacionalização do Ensino Superior e as Instituições de Ensino Privado no Brasil
}

\author{
Higher Education Internationalization and the Private Education \\ Institutions in Brazil
}

Maria Elisabete Guazzelli', Camila Sotello Raymundo', Deborah Varjabedian', Marco Akerman²

'Universidade Anhembi Morumbi (UAM) - São Paulo (SP), Brasil.

${ }^{2}$ Faculdade de Medicina do ABC (FMABC) - Santo André (SP), Brasil.

DOI: http://dx.doi.org/10.7322/abcshs.v40i3.810

\section{RESUMO}

A implementação de novas grades curriculares dos cursos de saúde nas universidades privadas é uma tarefa complexa. Ocupando espaço importante na formação profissional do ponto de vista qualitativo, as concepções pedagógicas nestas instituições obedecem à economia do conhecimento, sendo fortemente influenciadas pela internacionalização da educação e pelos desígnios do mercado. Essa lógica, crescente entre as instituições de ensino superior no Brasil, influencia não só os princípios de concepção e de implementação de modelos curriculares, mas também as estratégias e instrumentais pedagógicos e as relações docente-discente-instituição de ensino-população. Esse artigo pretende discutir alguns dos aspectos históricos e contemporâneos envolvidos na concepção da Universidade no Brasil e alguns dos impactos determinados pela internacionalização da educação superior. Observamos que, no processo de internacionalização da educação superior, a universidade privada brasileira experimenta uma relação assimétrica com os países centrais, ocupando uma posição subalterna, submetendo-se às decisões das corporações transnacionais.

Palavras-chave: educação em saúde; ensino; pesquisa; universidades; educação superior.

\section{ABSTRACT}

The implementation of new curriculum of health courses in private universities is a complex task. The pedagogical concepts in these institutions conform to the knowledge economy, being heavily influenced by the internationalization of education and the market designs becomes important in the vocational training from a qualitative point of view. This logic, growing between higher education institutions in Brazil, influences not only the principles of design and implementation of curricular models, but the pedagogical strategies, instruments, and relationships education population of teacher-student-institution. This article discusses some of the historical and contemporary aspects involved in designing the University in Brazil and some of the impacts determined by the internationalization of higher education. We note that in the process of internationalization of higher education, the Brazilian private university experience an asymmetrical relationship with the core countries, occupying a subordinate position, submitting to the decisions of transnational corporations.

Keywords: health education; teaching; research; universities; education, higher. 


\section{INTRODUÇÃO}

A concepção da grade curricular dos cursos da área da saúde não é uma tarefa fácil, e muito comumente a discussão quanto aos caminhos epistemológicos e estratégicos que a fundamentarão, resulta mais em uma experiência frustrante do que em um projeto gratificante, uma vez que, particularmente nos últimos dez anos, os moldes orientadores são concebidos de modo verticalizado, especialmente nas instituições privadas inseridas nas redes internacionais de ensino superior. Fatores fracamente explicitados atuam ora como facilitadores, ora como complicadores, na concepção do projeto curricular. $\mathrm{O}$ entendimento destes fatores obriga, antes, a compreensão do cenário contemporâneo, altamente complexo, no qual a universidade está inserida.

A reformulação curricular responde a uma lógica que ultrapassa questões profissionais ou epistemológicas, já que a universidade contemporânea está organizada a partir da concepção do conhecimento e da formação superior como "bem e serviço", submetidos à lógica do mercado. Algumas questões não ficam suficientemente claras aos atores envolvidos nesta tarefa. Por que rediscutir o currículo? De onde e de quem parte esta demanda? Para quem os resultados dessa mudança são dirigidos? Que necessidades e interesses ela pretende atender? Sob quais regras essa reformulação deve ser concebida?

A internacionalização da educação tem direcionado a concepção de modelos curriculares, as estratégias e os instrumentais pedagógicos e as relações docente-discente-instituição de ensino. Quando olhamos a história da Universidade no Brasil, vemos que a autonomia universitária nunca se efetivou plenamente. Em vários momentos, a universidade brasileira foi subalterna a interesses externos. Este estudo pretende compreender um pouco mais sobre a internacionalização e suas repercussões na educação superior contemporânea.

\section{A Universidade no Brasil: tensões entre a autonomia e os interesses políticos e econômicos ao longo da sua história.}

Criação específica da civilização ocidental, a instituição universitária teve papel fundamental na unificação da cultura medieval. Ao longo do século XIX, redefinida em suas atribuições, participou efetivamente no processo de consolidação dos Estados Nacionais. Enquanto a Espanha instalou universidades em suas colônias, Portugal nos deixou limitados às universidades da Metrópole, Coimbra e Évora ${ }^{1}$.

A resistência à criação da universidade e a qualquer iniciativa que apontasse para a independência cultural e política da colônia foi a tônica dos períodos colonial e monárquico. Mesmo quando sediou a Monarquia, o Brasil só assistiu ao funcionamento de algumas escolas superiores, onde prevalecia o caráter profissionalizante e o modelo europeu. Escolas como o Curso Médico de Cirurgia, na Bahia, em 1808, a Escola Anatômica, Cirúrgica e Médica, no Rio de Janeiro, matrizes das atuais Universidade Federal da Bahia (UFBA) e Faculdade de Medicina da Universidade Federal do Rio de Janeiro (UFRJ), e a Academia Real Militar do Rio de Janeiro, núcleo inicial da atual Escola de Engenharia da UFRJ, foram concebidas em resposta às necessidades de defesa militar da colônia, transformada em sede do governo português ${ }^{2}$.

Durante o Império, inúmeros projetos para a criação da universidade no Brasil foram frustrados. Enquanto alguns grupos defendiam um modelo de concepção napoleônico, onde caberia à Universidade controlar e centralizar o sistema de ensino superior, público e privado, outros defendiam a criação da universidade apoiada na "liberdade de ensino", com o maior acesso da iniciativa privada no campo da educação ${ }^{3}$

Na República, apesar do intenso debate em torno da educação, persistia a ordem política e social sustentada nas mesmas oligarquias regionais hegemônicas durante o Império. Em 1920 é instituída a Universidade do Rio de Janeiro, a partir da reunião das escolas Politécnicas e de Medicina do Rio de Janeiro e de duas Faculdades Livres de Direito já existentes. Apesar da pretensa autonomia didática e administrativa, havia pouca clareza nos pressupostos orientadores, e as escolas continuaram a funcionar de modo isolado, persistindo a polarização entre a padronização da educação superior e a autonomia acadêmica.

Quanto ao papel da universidade, de um lado destacava-se a importância da pesquisa e da disseminação científica, de outro a formação profissional. Prevaleceu o modelo voltado à modernização do pais com ênfase na formação da elite e na capacitação para o trabalho. Marcado pelo processo de industrialização e urbanização, o período de 1920 a 1945 assistiu à ampliação das funções do Estado, expandindo a rede pública de ensino primário ${ }^{3}$.

Até os anos 1920, o Rio de Janeiro concentrava a vida intelectual e o capital financeiro do país, incorporando à "cultura nacional" tudo o que chegava da Europa. Na passagem do século XIX para o Século XX, a intelligentsia brasileira em formação reivindicava a liderança moral da nação, mas mostrava-se incapaz de pensar uma nova sociedade frente as condições precárias da população. Parte desses intelectuais, passaram a pensar nas dinâmicas de uma sociedade contraditória, iniciando uma reflexão sobre o "caráter nacional" brasileiro ${ }^{4}$.

Transformações culturais, políticas, econômicas e sociais, e a configuração urbana, principalmente no Rio de Janeiro e em São Paulo, criaram relações ambíguas entre os domínios cultural e político. No cenário político conturbado dos anos 1920, o movimento modernista, criado por um grupo reduzido de intelectuais, influenciou a esfera cultural e política do país. Na busca de identidade cultural e social, contestou pilares estéticos dominantes em vários campos e influenciou também as ciências. Tentando ultrapassar o modelo hegemônico "europeizado" em direção a identidade social e cultural brasileira, buscou uma ligação entre a renovação cultural e a reforma da sociedade, mas enfrentou resistência, inclusive de setores do ensino superior nacional e internacional. Vivendo, simultaneamente, o sentimento de isolamento e de impotência diante da tarefa de reverter o "atraso" em que se encontrava o país, prevalecia a crença de 
que a reforma social deveria vir através da educação. Portanto, a ideia de chegar à reforma social por meio da reforma da educação não é contemporânea, e pode ser observada em diferentes momentos da história do Brasil ${ }^{4}$.

Desde a sua criação, a universidade no Brasil foi concebida mais como um instrumento político do que como um espaço de produção científica. Com a ambição de estabelecer a hegemonia cultural de São Paulo sobre o resto do país, na década de 1930, a Faculdade de Filosofia de São Paulo buscou criar um ensino de alto nível e estabelecer condições para o desenvolvimento da pesquisa científica. Preteriu os intelectuais brasileiros, e mais de dois terços das cátedras foram ocupadas por professores vindos da Alemanha, Inglaterra e França. Ao contrário, a Universidade do Distrito Federal, criada nesse mesmo período, formou o seu corpo docente a partir dos intelectuais brasileiros.

A ideia comum nos projetos das universidades de formar as elites que iriam orientar a nação não eram bem vistas pelo Estado Novo. A presença de professores estrangeiros no quadro docente da Universidade de São Paulo (USP) permitiu maior resistência a interferência do governo federal, mas ainda assim a Faculdade de Filosofia sofreu forte oposição das escolas profissionalizantes.

O crescimento do número de universidades de 5 em 1945 para 37 em 1964, e das instituições isoladas que aumentaram de 293 para 564, deveu-se, basicamente, a agregação de escolas profissionalizantes. O desenvolvimentismo dos anos 1950 impulsionou propostas de modernização do ensino superior, buscando adequar estas instituições às necessidades de desenvolvimento econômico e social do pais. O primeiro passo desse processo foi a criação, em 1947, do Instituto Tecnológico da Aeronáutica (ITA), que introduziu a contratação de professores sob as normas trabalhistas e adotou o molde das universidades americanas. A criação do ITA foi proposta no Relatório Smith e elaborado por uma comissão presidida pelo Brigadeiro Casimiro Monteiro e assessorada pelo professor Richard H. Smith, do Massachussets Institute of Technology.

Entre 1950 e 1960, intensificou-se o debate sobre a reforma universitária e as mobilizações em torno das reformas de base. A partir do governo militar, a reforma universitária se deslocou da reflexão sobre a sua responsabilidade social e política, em direção à lógica da racionalidade administrativa e econômica, sob uma perspectiva marcadamente repressiva. Assumindo a liderança do processo da modernização da universidade, o governo militar adotou a orientação desenvolvimentista, numa perspectiva essencialmente técnica. A reforma da educação proposta neste período foi traçada, fundamentalmente pelo projeto Ministério da Educação e Cultura/United States Agency for International Development (MEC-USAID), assentada em três pilares: educação e desenvolvimento, educação e segurança, educação e comunidade ${ }^{5,6}$.

Os acordos estabelecidos entre o MEC-USAID objetivavam estabelecer convênios de assistência técnica e cooperação financeira na educação brasileira. Firmados basicamente entre 1964 a 1968, os 12 acordos, pautados pela concepção da educação como pressuposto para o desenvolvimento econômico, abrangeram desde a antiga educação primária até o ensino superior ${ }^{6}$.

A agência americana forneceu as diretrizes políticas e técnicas como orientadoras do sistema educacional brasileiro, norteadas pelas necessidades do desenvolvimento capitalista internacional. Menos preocupados com a educação brasileira, a agência se ocupava em garantir a adequação do sistema brasileiro de ensino às metas da economia internacional, em especial aos interesses das grandes corporações norte americanas, enfatizando a racionalização, a eficiência e a produtividade. A busca prevalente por qualificação profissional atendendo as demandas de mercado, desencadeou a profissionalização obrigatória no segundo o grau e o surgimento de cursos superiores de curta direção, voltados a rápida formação de profissionais, menos voltados para a pesquisa e mais direcionados à lógica produtiva, empobrecendo a pesquisa e a capacidade reflexiva frente ao conhecimento e a sociedade. A formação superior visava antes preparar executantes do que desenvolver pesquisadores, aprofundando a dependência do ensino superior brasileiro às óticas internacionais, demarcando a posição subalterna do Brasil ${ }^{5}$.

No vínculo entre escola e empresa está predeterminada a natureza da mão de obra considerada necessária e, à medida em que a escola satura o setor de oferta frente a demanda, barateia-se a mão de obra. Esse vínculo formou profissionais brasileiros menos qualificados do que aqueles formados nos países centrais, criando uma reserva de profissionais, diminuindo o valor dos salários, e formando profissionais mais "dóceis"

A presença da empresa dentro da lógica do ensino superior determinou a estruturação das escolas segundo o princípio de organização, tornando-as burocratizadas e hierarquizadas, reforçando a histórica ausência de autonomia universitária. Prevalece a óptica da auto sustentação na geração de lucros, permitindo a proliferação de escolas privadas, propostas pelas empresas segundo as suas necessidades.

No estado neoliberal dos anos 1980, a educação superior é entendida como parte do problema econômico que comprometia a competitividade econômica. A globalização trouxe novas recomendações para a organização da vida econômica e social, às relações internacionais e à inserção do Estado. Transformados em serviços sociais não exclusivos do Estado e sob a óptica da competição de mercado, as universidades passam manejar a educação superior como objeto da lógica privada, mais do que da pública. Se antes o direcionamento da educação superior no Brasil havia sido pautado por aspectos políticos e econômicos externos, agora as diretrizes são determinadas pelo mercado ${ }^{7}$.

A acumulação flexível e a liberação econômica iniciada nos países centrais no final dos anos 1970 determinou mudanças na educação superior, influenciadas por organismos multilaterais de crédito como o Fundo Monetário Internacional (FMI), Banco Mundial (BM) e Banco Interamericano de Desenvolvimento (BID), sob a orientação dos países centrais. O papel de Estado como provedor dos serviços sociais como educação e saúde foi substituído pelo de "regulador". 
A iniciativa privada, na lógica de mercado, assumiu aquelas atividades que antes pertenciam ao Estado ${ }^{7}$.

As mudanças na educação superior nas últimas décadas do século $\mathrm{XX}$, como a expansão do número das instituições de ensino superior e das matrículas do setor privado, seguiram o modelo centrado na heteronomia, no qual setores externos subordinaram as universidades na definição da missão, da agenda e dos seus "produtos", de modo que a prática cotidiana universitária passou a ser definida pela lógica do mercado. As políticas de educação superior fortaleceram a competitividade econômica, a busca de inovação de "produtos" e "processos", a ênfase em currículos ligados às necessidades do mercado, a preparação dos alunos voltada para o mundo do trabalho e a efetiva gerência do trabalho institucional e docente, burocratizando as atividades dos professores.

Observou-se a redução dos orçamentos, a deterioração da infraestrutura, a ampliação da privatização, a ênfase na pesquisa aplicada, o esvaziamento das disciplinas que se apoiam na reflexão e a valorização daquelas voltadas para o mercado e para o pragmatismo, a ampliação da concorrência entre as diferentes instituições de ensino superior e dentro de uma mesma instituição, entre os diferentes cursos.

\section{A internacionalização e o novo cenário da educação superior.}

A sociedade contemporânea, orientada pela internacionalização e globalização, experimenta uma nova ordem pautada fundamentalmente em termos econômicos que repercute profundamente no ensino superior. A compreensão desse fenômeno exige, antes, que se discuta não só o papel do conhecimento e da informação em nossa sociedade, mas a própria compreensão do que é esse conhecimento e informação e dos objetivos e representações sociais a eles atrelados. Inserindo-se na sociedade global, a universidade passa a valorizar o capitalismo acadêmico, numa lógica de economia do conhecimento ${ }^{8}$.

O papel das corporações transnacionais no processo de globalização e internacionalização da educação é particularmente importante. Mesmo quando estas corporações tem uma base claramente nacional, elas são orientadas aos mercados e aos lucros globais. Estas corporações são instrumentais na difusão de novas tecnologias da educação e são importantes protagonistas dos mercados financeiros. Estados nacionais frágeis estabelecem relações simbióticas com esses poderosos atores transnacionais, ocupando um lugar subalterno. A lógica é a de submissão acadêmica e intelectual, não cabendo às universidades brasileiras o papel decisório ou protagonista, uma vez que a sociedade de economia global, direcionada pelas grandes empresas comerciais transnacionais e por organismos multilaterais que fornecem o substrato financeiro, político e ideológico, é movida por conhecimentos de caráter utilitário, potencializado pelas tecnologias informacionais.

A internacionalização da educação está submetida a mesma lógica vigente no trato de outros "produtos" que não o conhecimento ou a formação superior. Seus impactos não se fazem sentir apenas no espaço macrossocial, mas envolve também mudanças profundas nas trajetórias pessoais, criando novas tensões e demandas. O individualismo, eixo central dos projetos liberais, ganha na contemporaneidade novas atualizações e roupagens.

A tradição e os costumes exercem fraca influência, e se no passado as identidades pessoais eram formadas no contexto da comunidade, agora, nesse "novo" individualismo, cabe a cada pessoa, de forma ativa, se auto construir e estabelecer sua própria identidade. $\mathrm{O}$ individualismo, desse modo, constrói sujeitos auto definidos e autocontrolados, com imensos mundos interiores e subjetivos, instituídos de modo isolado e separado do resto. $\mathrm{O}$ individualismo determina atitudes e comportamentos onde cada pessoa busca identidades fugazes e frágeis. A cada momento, o "constructo identitário" torna-se obsoleto, exigindo assim uma nova ação e construção. O que permanece constante é a sensação de impermanência e obsolescência, impelindo o sujeito a novas, e incertas, buscas.

No projeto de internacionalização da educação superior, a perspectiva individualista manifesta-se, por exemplo, através da crescente demanda por metodologias ativas de aprendizagem, pela educação continuada e pela crença que é o aluno o ator principal no processo de construção do próprio conhecimento. É a ele que cabe buscar soluções para seu aprendizado e o protagonismo na construção do conhecimento. O professor assume, então, o papel de facilitador do aprendizado. Do ponto de vista pragmático, este cenário busca corrigir as lacunas que os programas de formação superior, cada vez mais curtos e mais enxutos, fazem surgir.

Nessas ações, mais do que desencadear o aprofundamento sobre premissas teóricas e a reflexão sobre conceitos e temas complexos, busca-se desenvolver a habilidade para resolver problemas. As ligações interpessoais, como por exemplo, nas metodologias de aprendizagem entre pares, cumprem metas pragmáticas para desenvolver a habilidade de trabalho em equipe, atendendo a metas menos acadêmicas e mais organizacionais. A busca por soluções de problemas propostos neste processo de aprendizagem tende a resolver-se na superficialidade e no imediatismo, uma vez que novas demandas intensas e urgentes, características prementes do cenário contemporâneo, exigem respostas e soluções rápidas, quase sempre desprovidas de reflexões mais profundas.

O cenário contemporâneo traz uma nova ordem comunitária, resultante das redes de interação e das formas de conexão das comunidades contemporâneas. Ao empregarem novas tecnologias em comunicação, as comunidades também se tornam fluidas, alterando suas inserções no tempo e no espaço, tornando-se descentralizadas e erigindo novas dimensões éticas e políticas. Dentro dessas novas modalidades de comunicação e de relações interpessoais surgem rituais de encontros fugazes, prioritariamente presentes para diminuir as ansiedades geradas pela solidão cotidiana e pelas sensações de não pertencimento e de desenraizamento.

No entanto, essas novas relações falham em proporcionar a mínima segurança para lidar com as carências inerentes à condição humana, gerando a sensação de impotência do indivíduo contemporâneo, e não permitem a real formação de comunidades éticas. Dispersam os 
movimentos de sociabilidade e acabam por manter a atmosfera de solidão que reassume rapidamente seu posto ao final destes rituais. A radicalização da velocidade da lógica produtiva do mercado globalizado vem acompanhada por outro mecanismo de desencaixe: simultaneamente, os novos meios de informação e de comunicação nos permite estar conectado a vários lugares.

Neste cenário, predomina o enfraquecimento na negociação de interesses comuns. Como consequência, o espaço público já não pode ser entendido como um espaço civil, uma vez que a interação está dispensada do cenário. O esvaziamento do espaço público e a impossibilidade de concretude política são características de uma sociedade pautada pelo consumo, onde as preocupações e motivações sociais estão voltadas para os interesses individuais e privados, enfraquecendo o engajamento político e as reflexões em torno de interesses coletivos. A fragilização do espaço público - tomado como lugar natural do político - leva à decadência do diálogo e da capacidade de negociar interesses comuns. Uma triste consequência desse cenário é que os encontros intersubjetivos se prestam muito mais às trocas de informações que permitem algum tipo de "consumo".

A educação superior faz parte de uma agenda de consolidação e expansão da economia global, e está situada nesta trama contemporânea. Vive tensões e conflitos, uma vez que os atores envolvidos no contexto educacional se deparam com inúmeros paradoxos: a educação já não se apresenta aos jovens como caminho inequívoco de sucesso profissional e econômico; os docentes não compreendem claramente as novas demandas impostas no cenário educacional; os currículos, conteúdos e práticas pedagógicas não parecem corresponder a realidade . $^{8}$

Distanciados do centro decisório, docentes e discentes são submetidos a regras e a metas que parecem não fazer sentido, e que, por responderem às lógicas do mercado e ao utilitarismo, são extremamente fluídicas.

Segundo Dias Sobrinho ${ }^{8}$, a economia do conhecimento só se tornou exequível por meio da redefinição dos papéis da universidade, pois depende fundamentalmente da produção científica e tecnológica. Ela valoriza predominantemente os conhecimentos que apresentam critérios de utilidade e aplicabilidade às organizações mercantis. Diferentemente das práticas acadêmicas do passado, o mundo acadêmico e científico quer tornar-se visível às organizações econômicas, aos operadores dos sistemas de avaliação e financiamento e ao público em geral. Ao interesse público, prevalece o interesse privado e particular e o desenvolvimento da habilidade e competência de resolver problemas concretos torna-se uma premissa mais importante do que a reflexão sobre teorias ${ }^{8}$.

As grandes universidades e centros de pesquisa localizados nos países ricos e centrais se configuram como os grandes produtores de pesquisa, criando redes de colaboração internacional, ampliando seu poder e capacidade de influenciar o ensino superior nos países periféricos. Aos docentes são impostas inúmeras demandas de qualificação profissional, alinhadas com as necessidades momentâneas das empresas, com a manutenção da empregabilidade e com as necessidades de adaptação às novas demandas do mercado. Tornam-se constantes a diversificação dos produtos oferecidos pelas universidades internacionalizadas, a reestruturação da grade curricular, o surgimento de novos cursos e campos profissionais, o surgimento de novas práticas e ferramentas pedagógicas em direção a qualificação e requalificação de competências e habilidades laborais. O ensino e suas dinâmicas encontram-se reificadas.

Sob o pretexto de aumentar a diversificação e a flexibilidade do ensino superior, esconde-se a perda da capacidade reflexiva e crítica e as estratégias de horizontes mais amplos e duradouros das instituições educativas, empobrecendo o desenvolvimento integral dos indivíduos, com a equidade e o fortalecimento da cidadania.

Um fenômeno importante na economia do conhecimento é o surgimento da "universidade empreendedora". Nesta perspectiva, a universidade, ao assumir um caráter empresarial, adota a lógica administrativa que aceita a ideia de comercialização do saber, ocupa-se em identificar com clareza os núcleos centrais das oportunidades de desenvolvimento, busca a eficácia social e a utilidade profissional. Nesse modelo de universidade a inovação constitui-se como pilar de sustentação, incorporando jargões empresariais à lógica acadêmica ${ }^{8}$.

A liberdade nos processos de produção de conhecimento experimentada pela universidade inserida numa lógica de internacionalização exige um controle mais rígido em relação ao produto. Desse modo, ao ensino superior tem se tornado muito mais burocrático e os docentes estão muito mais ocupados com relatórios e outros instrumentos de controle do que envolvidos em reflexões críticas. Quanto mais as instituições de ensino superior se submetem às demandas externas, mais comprometida é a sua autonomia na determinação de seus objetivos e dos caminhos acadêmicos a serem trilhados.

Isso explica, em grande parte, a centralidade que a acreditação, a qualidade e participação em rankings vêm progressivamente adquirindo. $\mathrm{O}$ Estado aumenta seu poder de supervisão, avaliação e regulação, permitindo mais liberdade de processo às instituições de ensino superior (gestão, modelos organizacionais, meios) e controlando os produtos mediante indicadores de performance, produtividade, análise de relação custo-benefício e desempenho estudantil.

\section{CONSIDERAÇÕES FINAIS}

É claro que o curto espaço de um artigo é insuficiente para uma reflexão mais densa sobre um tema que apresenta tantos desdobramentos. Mas, apesar disso, ele se presta a trazer à tona um desconforto que inúmeras vezes é experimentado subjetivamente entre os atores envolvidos na universidade, em especial aquela da iniciativa privada. Apesar das tensões e da fragilização da universidade enquanto espaço de reflexão, não podemos perder de vista que este é um lugar que pode retomar o debate em torno das ideias, da sociedade e do papel do conhecimento, ultrapassando a perspectiva essencialmente utilitária.

Se o processo de internacionalização é irreversível, cabe perguntar como a universidade brasileira pode migrar de uma posição subalterna para o protagonismo intelectual, buscando, nas parcerias internacionais, dinâmicas de trocas simétricas de conhecimento. 


\section{REFERÊNCIAS}

1. Mendonça AWPC. A Universidade no Brasil. Rev Bras Educ. 2000;(14):131-150.

2. Fávero MLA. A Universidade no Brasil: das origens à Reforma Universitária de 1968. Educar. 2006;(28):17-36.

3. Paim A. Por uma Universidade no Rio de Janeiro. In: Schwartzman S. Universidade e Instituições Científicas no Rio de Janeiro. Brasília: Conselho Nacional de Desenvolvimento Científico e Tecnológico (CNPq); 1982; p.17-96.

4. Martins L. A gênese de uma intelligentzia: os intelectuais e a política no Brasil. Rev Bras Ciênc Sociais. 1987:2(4):65-87.
5. Chaui M. A reforma do ensino. Discurso. 1978;8:148-59.

6. Alves MM. Beabá dos MEC-USAID Rio de Janeiro: Gernasa, 1968.

7. Sguissardi, V. Educação superior no limiar do novo século: traços internacionais e marcas domésticas. Revista Diálogo Educacional. 2002;3(7):121-44.

8. Sobrinho JD. Universidade e novos modos de produção, circulaçãoeaplicação do conhecimento. Avaliação. 2014;19(3):64362. http://dx.doi.org/10.1590/S1414 40772014000300007 